\title{
Stochastic Optimization for Electric Power Generation Expansion Planning with Discrete Climate Change Scenarios
}

\author{
Shuya $\mathrm{Li}^{1}$, David W. Coit ${ }^{1 *}$, Frank Felder ${ }^{2}$ \\ ${ }^{1}$ Rutgers University, Industrial \& Systems Engineering Department, School of Engineering, Piscataway, NJ \\ ${ }^{2}$ Rutgers University, Bloustein School of Planning and Public Policy, New Brunswick, NJ
}

Abstract - This research is dedicated to the study of electric power system generation expansion planning considering uncertainty of climate change. Policy makers are increasingly concerned about the effects of climate change and its impact on human systems when making decisions. Electric power Generation Expansion Planning (GEP) problems that determine the optimal expansion capacity and technology under particular technical constraints, given cost and policy assumptions, are undoubtedly among those decisions. The best approach to comprehensively model climate change uncertainties, and to optimize the generation planning under uncertainty needs to be rigorously studied. In this research, a preliminary GEP model is proposed with available input data from various sources. Discrete scenarios of possible climate change outcomes are defined and optimization models are formulated to specifically model uncertainty. Relationships between climate change and GEP parameters are defined for each scenario to consider their effects. The preliminary GEP model is then solved under each scenario to identify the climate change impact on generation expansion planning decisions. Two related optimization models are then presented and solved to find the optimal results under uncertainty: Model 1 is expected total cost minimization, and Model 2 is maximum regret minimization. Both models find compromise solutions that are suitable for all scenarios, which avoid the possible risk associated with a poor decision that is only optimal for one particular scenario, or only for an average climate change forecast.

Keywords: Climate change, generation expansion planning, scenarios

\footnotetext{
* Corresponding author: David W. Coit, email: coit@rci.rutgers.edu, telephone: 848-445-2033
} 


\section{Introduction}

An electric power system is a network of generation, transmission, distribution and load components. The electricity Generation Expansion Planning (GEP) problem involves the selection of generation technology options to be added to an existing system, and when and where they should be constructed to meet the growing energy demand over a planning time horizon [1]. The problem is solved to ensure an economic, reliable and environmentally acceptable supply over a given planning horizon based on particular technical constraints, and cost and policy assumptions.

Climate change has generated significant research interest for electric power system planning as policy makers are increasingly concerned about its effects on this critical system. Various initiatives, policies and regulations have been launched to address this issue, such as Regional Greenhouse Gas Initiative (RGGI), Eastern Interconnection Planning Collaborative (EIPC), Renewable Portfolio Standard (RPS) and the most recent Environmental Protection Agency's Clean Power Plan (CPP). A regional GEP model provides a useful tool for power system uncertainty modeling as well as reliability and risk management for both market-driven and vertical integrated electricity generation. In countries and regions that have competitive electricity markets, solution of GEP may not be explicitly useful for a utility or government agency. That being said, there are still many parts of the world that do not have electricity markets and the GEP is still directly applicable, or if even they do have competitive markets, GEP solutions can help inform environmental policies such as greenhouse gas reduction policies (e.g., CPP) or renewable energy policies (e.g., feed-in-tariffs or RPS).

It must continually be assured that sufficient and flexible generation capacity is planned and constructed to meet anticipated growing demand and unpredictable climate disasters, recognizing that the costs associated with short-term variability are absorbed and passed on to consumers [2]. Therefore, we propose in this paper both risk-neutral and risk-averse approaches addressing different policy making considerations for GEP optimization under climate change 
uncertainty. There are several major climate variables that are relevant to the power system [3], including temperature, precipitation and frequency of extreme events, which are fully addressed in this paper. Higher temperatures will increase demand for summer cooling, and thus peak loads, and decrease heating demands in winter. Seasonal and long-term changes in patterns of precipitation, river flow, runoff and snowpack will impact cooling water availability for electricity generation. Extreme events also affect electricity generation, transmission and distribution facilities. While the extent of climate change remains uncertain, the model results can provide valuable insights and lessons-learned for appropriate adaptation and mitigation in response to global climate trends.

\subsection{Background}

Greenhouse gas emissions, mainly carbon dioxide, associated with the production and use of energy are widely believed to be a primary cause of global warming, and in turn, broader climate change, will influence our production and use of energy [5]. The interaction of climatic, environmental and human factors makes the effects of climate change complex and uncertain. Refs. [5-10] provide background on climate change projections, implications of future risk management with possible mitigation and adaptation measures, as well as, comprehensively project and assess the impacts of climate change from a broader perspective of intergovernmental agencies/organizations and U.S. government.

Researchers have started to study those impacts on power systems recently, but according to [11], "there is a dearth of literature on assessment studies that focus on climate change impacts on electric power sector at a national, regional or state-level." Chandramowli and Felder [11] summarize large amount of references that study the climate change impacts on electricity demand and supply, in which most reviewed papers such as [12-14] only adopt simple statistical regression based on historical data without fully considering the uncertainty of climate outcomes. The Sixth Northwest Conservation and Electric Power Plan [15] models climate change as a random variable and incorporate climate change uncertainty into the model as a 
random variable with a relative likelihood of each climate scenario. U.S. Department of Energy [3], U.S. Climate Change Science Program [16] and Urban and Mitchell [17] assess the vulnerabilities and impacts in the energy sector, and the adaptation responses and future opportunities. While [3,15-17] do provide certain assessments on climate change impacts, their findings are theoretical or conceptual without collecting/validating data and establishing optimization models. Therefore, this research serves as the initiative or motivation to develop valid optimization GEP models for different policy makers that involve multiple aspects of climate change uncertainty on a regional level.

Least-cost and multi-objective GEP problems, as well as different solution techniques have been extensively studied in the past forty years [1, 18-27]. Whereas most previous studies employ deterministic modeling, it is prudent to incorporate the uncertainty in future conditions. There are significant and meaningful uncertainties involved in GEP [28], and various methodologies have been proposed to address this uncertainty. Similar ideas can be adopted to address uncertainties of climate change. Several references $[1,29,30]$ propose mixed integer linear multi-objective models, Monte Carlo simulation, corrected normal boundary intersection (CNBI) method with Pareto optimal solutions and scenario-based sensitivity analysis, respectively. Cazalet [31] and Borison et al. [32] introduce a decomposition method for stochastic problems. Gorenstin et al. [33] and Malcolm et al. [34] describe the discrete scenarios method. In this method, several scenarios with probabilities are defined or selected in place of a deterministic equivalent approach, and the stochastic optimization aims to identify an optimal solution that gives satisfactory results for all scenarios, which is a "robust model."

Buehring et al. [35] introduce STATS (Stochastic Analysis of Technical Systems) model based on Monte Carlo simulation. Dynamic programming models used in [36-38] are combined with discrete time Markov chains, fuzzy technique and Benders decomposition separately. Pereira et al. [39] consider system dynamics that could capture the long-term evolution of demand and price, which then are considered in the generation expansion planning process. 
Ahmed et al. [40] use discrete time stochastic processes with a finite probability space.

Future climate cannot practically be precisely modeled by a continuous joint probability density functions, so Monte Carlo simulation is not practical in this research, because there are no underlying distributions to sample from. Instead, the ideas from [33-34] represent a better and efficient alternative. Thus, an approach using discrete scenarios and stochastic optimization is proposed in this paper. Scenario analysis is a common tool in the field of stochastic programming to accommodate and model future uncertainty through a finite set of scenarios with a discrete probability distribution. Each scenario corresponds to the realization of a specific set of the uncertain variables with an associated probability. Scenarios should be designed to characterize the realistic range of all relevant sources of uncertainty but with a computational acceptable number. Extreme scenarios with low probability should be included for the consideration of model robustness. There exist two common methods to describe the set of all possible scenarios. In the interval data case, each numerical parameter can take any value between a lower and an upper bound. In the discrete scenario case, the scenario set is described explicitly [41]. In our research, the emphasis is on discrete scenarios. Two formulations are given in this paper: expected total cost minimization and maximum regret minimization. "Regret" is also called "opportunity loss" in some literature, and maximum regret is then the worst-case opportunity loss. Averbakh [42] defines the regret as the absolute (or relative) deviation of the objective function value, based on a compromise solution, from the best possible one for a particular scenario. Gorenstin et al. [33], Bean and Hoppock [43] and Jiang et al. [44] give examples of maximum regret minimization formulations.

\subsection{Problem Statement}

Climate change is and will be affecting new power plant investment decisions and electricity generation system in many uncertain and unanticipated ways. The power system needs to be more reliable, more resilient, cost-effective and environmentally friendly when exposed to higher temperature, more or less precipitation and more intense and frequent extreme 
events [4]. This research is motivated by the worldwide climate change concerns and various climate policy studies of EIPC.

As stated by EPIC (http://www.eipconline.com/home.html): "EIPC was initiated by a coalition of regional Planning Authorities in the Eastern Interconnection to model the impact on the grid of various policy options determined to be of interest by state, provincial and federal policy makers and other stakeholders. This work will build upon, rather than replace, the current local and regional transmission planning processes developed by the Planning Authorities and associated regional stakeholder groups within the entire Eastern Interconnection."

EIPC has conducted a wide range of studies and scenario analyses primarily focusing on the impact of different policies on the GEP process. However, few research studies (including EIPC) have addressed the importance of modeling climate change as a random variable and its impacts in the processes of decision making. Some researchers have investigated uncertain climate change using simple statistical models but only considered the demand aspect of the GEP problem. In fact, many other elements in generation expansion planning are impacted by climate change, such as transmission capacity, generation capacity, maintenance, and so on. These should also be specifically and systematically studied. We believe the new models proposed in this paper, which carefully model each of these factors in the GEP processes, could provide distinct advantages and insights for all interested stakeholders.

To rigorously consider the uncertainty of climate change, this study defines and applies a discrete scenarios method. The discrete scenarios represent possible climate change outcomes. The objective is to select a compromise solution under discrete climate scenarios, avoiding the possible risk associated with a poor decision that is only optimal for one particular scenario or only the average climate change. Possible risks include investing in too much capacity when it is not required or not meeting demands and/or reliability requirements once a particular scenario occurs in the future. This can then be represented mathematically as the "regret." In either case, "regret" can be interpreted as the difference between the optimal cost if we somehow knew in 
advance which particular scenario will occur at the time of decision, and the realized cost (including penalty costs) given a compromise solution is chosen instead considering the uncertainty.

This study starts with a preliminary GEP model with all the variables and parameters defined with available data from multiple sources, which includes existing capacities, projected future electricity demands and peak demands, emission and transmission limits, etc. Then the uncertainty of climate change is introduced through discrete climate scenarios, as the parameters that are directly or indirectly affected by climate change are varied under different scenario assumptions.

The methodology of discrete scenarios is used to make the problem tractable and solvable instead of attempting to define and quantify some unknown multi-dimensional continuous probability density functions for future environmental variables. The preliminary GEP model is initially solved for each scenario individually to identify the climate change impact on the initial generation expansion planning decision. After that, two related optimization models are presented and solved to determine the optimal results under uncertainty: Model 1 is expected total cost minimization, and Model 2 is maximum regret minimization. In both models, constraints are used for all scenarios by incorporating penalty costs for each scenario. Sensitivity analyses and comparisons between results are conducted and conclusions are made afterwards.

As EIPC is the major data source for this research, the study scope is limited to New England (Maine, New Hampshire, Vermont, Massachusetts, Rhode Island, Connecticut), New York State and the PJM Interconnection (all or most of Delaware, District of Columbia, Maryland, New Jersey, Ohio, Pennsylvania, Virginia and West Virginia, parts of Indiana, Illinois, Kentucky, Michigan, North Carolina and Tennessee) [4].

\subsection{Nomenclature}

$\underline{\text { Decision Variables }}$

$x_{y, t, r_{1}, i} \quad$ Generation amount of generation type $i$ in region $r_{1}$ in time period $t$ in year $y(\mathrm{MWh})$ 


\begin{tabular}{|c|c|}
\hline$s_{y, r_{1}, i}$ & Investment amount of generation type $i$ in region $r_{1}$ in year $y(\mathrm{MW})$ \\
\hline$f_{y, t, r_{1}, r_{2}}$ & Transmission flow from region $r_{1}$ to $r_{2}$ in time period $t$ in year $y(\mathrm{MWh})$ \\
\hline$U D_{y, t, r_{1}, j}$ & Unmet demand in region $r_{1}$ in time period $t$ in year $y$ in scenario $j(\mathrm{MWh})$ \\
\hline$U G_{y, t, r_{1}, i, j}$ & $\begin{array}{l}\text { Unavailable amount of generation type } i \text { in region } r_{1} \text { in time period } t \text { in year } y \text { in scenario } j \\
(\mathrm{MWh})\end{array}$ \\
\hline$U R_{y, r_{1}, j}$ & Unmet reserve margin capacity requirement in region $r_{1}$ in year $y$ in scenario $j(\mathrm{MW})$ \\
\hline$U T_{y, t, r_{1}, r_{2}, j}$ & $\begin{array}{l}\text { Unavailable transmission amount from region } r_{1} \text { to } r_{2} \text { in time period } t \text { in year } y \text { in scenario } j \\
(\mathrm{MWh})\end{array}$ \\
\hline Maxregret & Maximum regret \\
\hline \multicolumn{2}{|l|}{$\underline{\text { Indices }}$} \\
\hline$y, u$ & Years \\
\hline$t$ & Time periods in each year \\
\hline$r_{1}, r_{2}$ & Regions \\
\hline$i$ & Generation types \\
\hline$n$ & Renewable generation types (subset of $i$ ) \\
\hline$e$ & Emission gases \\
\hline$j$ & Scenarios \\
\hline \multicolumn{2}{|l|}{$\underline{\text { Parameters }}$} \\
\hline$r$ & Interest rate/discount rate \\
\hline$J$ & Number of scenarios \\
\hline$Y$ & Number of years \\
\hline$T$ & Number of the time periods in a year \\
\hline$R$ & Number of regions \\
\hline$I$ & Number of generation types \\
\hline$N$ & Number of renewable generation types \\
\hline$E$ & Number of emission gases $\left(\mathrm{CO}_{2}, \mathrm{SO}_{2}, \mathrm{NO}_{\mathrm{x} \ldots}\right)$ \\
\hline$c_{y, i}$ & Generation variable cost for generation type $i$ in year $y(\$ / M W h)$ \\
\hline$a_{y, i}$ & Investment cost for generation type $i$ in year $y(\$ / M W)$ \\
\hline$p_{j}$ & Probability of scenario $j$ \\
\hline init $_{r_{1}, i}$ & Initial capacity of generation type $i$ in region $r_{1}$ at the beginning of the time horizon (MW) \\
\hline fnew $_{y, r_{1}, i}$ & Forced new capacity of generation type $i$ in region $r_{1}$ on-line in year $y(\mathrm{MW})$ \\
\hline fretire $_{y, r_{1}, i}$ & Forced retirement capacity of generation type $i$ in region $r_{1}$ with retirement year $y(\mathrm{MW})$ \\
\hline$g_{y, i}$ & Fixed operation and maintenance cost for existing generation type $i$ in year $y(\$ / M W)$ \\
\hline$h_{y, i}$ & Fixed operation and maintenance cost for new generation type $i$ in year $y(\$ / M W)$ \\
\hline$\varphi_{y, t, r_{1}}, \varphi_{y, t, r_{1}, j}$ & Demand in region $r_{1}$ in time period $t$ in year $y$ in scenario $j(\mathrm{MWh})$ \\
\hline$d_{y, t, i,} d_{y, t, i, j}$ & $\begin{array}{l}\text { Outage rate of generation type } i \text { in time period } t \text { in year } y \text { in scenario } j \text { (i.e. the proportion of } \\
\text { time when a generation unit is not available for service caused by equipment failures, weather } \\
\text { disruptions or preventive and corrective maintenance activities, etc.) }\end{array}$ \\
\hline hours $_{t}$ & Hours in time period $t$ \\
\hline
\end{tabular}




\begin{tabular}{|c|c|}
\hline$c f_{y, t, r_{1}, i}, c f_{y, t, r_{1}, i, j}$ & $\begin{array}{l}\text { Capacity factor for generation type } i \text { in region } r_{1} \text { in time period } t \text { in year } y \text { in scenario } j \text { (i.e. } \\
\text { the ratio of actual usable capacity of a generation unit to its nameplate capacity given its } \\
\text { thermal efficiency or fuel availability) }\end{array}$ \\
\hline peak $_{y, r_{1}}$, peak $_{y, r_{1}, j}$ & Peak load (demand) in year $y$ in region $r_{1}$ in scenario $j(\mathrm{MWh})$ \\
\hline$m_{y, r_{1}}, m_{y, r_{1}, j}$ & Reserve margin for region $r_{1}$ in year $y$ in scenario $j$ \\
\hline$M I N_{y, r_{1}, n}$ & Minimum generation percentage requirement of renewable type $n$ for region $r_{1}$ in year $y$ \\
\hline $\operatorname{TMIN}_{y, r_{1}}$ & Yearly minimum renewable generation percentage requirement for region $r_{1}$ in year $y$ \\
\hline$E M_{e, i}$ & Amount of emission gas $e$ from generation type $i(\mathrm{lbs} / \mathrm{MWh})$ \\
\hline$R L E M_{e, y, r_{1}}$ & Regional limit for emission gas $e$ in region $r_{1}$ in year $y(\mathrm{lbs})$ \\
\hline$T L_{y, r_{1}, r_{2}}, T L_{y, r_{1}, r_{2}, j}$ & Transmission limit from region $r_{1}$ to $r_{2}$ in year $y$ in scenario $j$ (MW) \\
\hline$C L_{y, r_{1}, i}$ & Yearly construction limit of generation type $i$ in region $r_{1}$ in year $y(\mathrm{MW})$ \\
\hline$V D_{y}$ & Penalty cost of unmet demand in year $y(\$ / M W h)$ \\
\hline$V R_{y}$ & Penalty cost of unmet reserve margin requirement in year $y(\$ / M W)$ \\
\hline Optimal $_{j}$ & Expansion cost of optimal solution under scenario $j(\$)$ \\
\hline
\end{tabular}

\section{Deterministic Climate Change Model}

A traditional deterministic GEP model is initially constructed and then the uncertain climate variables and the definition of discrete climate scenarios are introduced in the latter part of this section. We identify three of the most relevant climate variables that can have separate or combined effects on six of the GEP decision variables, which are then mapped into five discrete climate scenarios. For each individual climate scenario, every climate variable is assigned a value based on long-term climatic research and projections, i.e., each climate scenario corresponds to a unique set of uncertain GEP parameters. At the conclusion of this section, the deterministic linear programming model is solved individually for each scenario, providing necessary input for the stochastic model in Section 3.

\subsection{Initial deterministic GEP model}

The initial GEP model problem is a standard deterministic linear programming model that is well developed in this field. A typical deterministic GEP model usually contains: a) an economic objective, b) a set of decision variables representing the design options such as resource amounts, timing and location, c) a set of constraints including physical, regional and capacity limitations, demand and reliability requirements, environmental, financial and 
regulatory considerations. The objective is to minimize the net present value of costs associated with an expansion planning solution. The total costs include three parts: investment costs of new construction, electricity generation costs, and operation and maintenance (OM) costs.

The GEP has three sets of decision variables: investment amount, generation amount and transmission amount. A selection of available generation technologies is given with different investment costs, operating costs, outage and emissions, while the regional specifications are also provided. By selecting the right type of technology and appropriate amount of capacity to be added to the power grid at the right time and place, the objective is to minimize the net present value of investment costs of new construction, fixed $\mathrm{OM}$ costs assuming different costs for existing and new units due to technology advances, and variable costs (i.e. fuel costs and variable OM costs) over the planning horizon, without violating any of the constraints. In this model, it is assumed that the transmission system will not be expanded and is limited by existing infrastructure constraints.

GEP models all have supply and demand constraints, whereas in this research, local generation plus the net transmission inflow is required to meet the regional demand. Meanwhile, total generation amount is limited by capacity constraints, given as the total installed rated capacity discounted by a physical capacity factor and assumed outage rate for each type of technology.

From the perspective of regional planning, sufficient supply should be included in the grid in case of unplanned events or force majeure. Reliability requirements are modeled as a function of reserve margin, represented by an extra amount of generation capacity built into the power system. Because power generation is affected by different weather, seasonal spikes or fuel supply conditions, the reserve margin requirements also vary from region to region.

The deterministic model has some environmental policy limits as well. Some states or regions specify minimum percentage of electricity generation from one particular renewable resource or renewables as a whole. The regional $\mathrm{SO}_{2}, \mathrm{NO}_{\mathrm{X}}$, and $\mathrm{CO}_{2}$ emissions from all type of 
generation facilities are restricted in those areas, while there exist regulatory construction limits for certain period of time in some areas.

The optimization model is as follows.

$$
\begin{aligned}
\min C O S T & =\sum_{y=1}^{Y}\left(( 1 + r ) ^ { - y + 1 } \left(\sum_{t=1}^{T} \sum_{r_{1}=1}^{R} \sum_{i=1}^{I} x_{y, t, r_{1}, i} c_{y, i}+\sum_{r_{1}=1}^{R} \sum_{i=1}^{I} s_{y, r_{1}, i} a_{y, i}\right.\right. \\
& \left.\left.+\sum_{r_{1}=1}^{R} \sum_{i=1}^{I}\left(\sum_{u=1}^{y}\left(s_{u, r_{1}, i}+\text { fnew }_{u, r_{1}, i}\right)\right) h_{y, i}+\sum_{r_{1}=1}^{R} \sum_{i=1}^{I}\left(\text { init }_{r_{1}, i}-\sum_{u=1}^{y} \text { fretire }_{u, r_{1}, i}\right) g_{y, i}\right)\right)
\end{aligned}
$$

s.t.

$$
\begin{aligned}
& \sum_{i=1}^{I} x_{y, t, r_{1}, i}-\sum_{r_{2}=1}^{R} f_{y, t, r_{1}, r_{2}}+\sum_{r_{2}=1}^{R} f_{y, t, r_{2}, r_{1}}=\varphi_{y, t, r_{1}} \quad \forall y, t, r_{1} \\
& x_{y, t, r_{1}, i} \leq\left(\text { init }_{r_{1}, i}+\sum_{u=1}^{y}\left(s_{u, r_{1}, i}+\text { fnew }_{u, r_{1}, i}-\text { fretire }_{u, r_{1}, i}\right)\right) c f_{y, t, r_{1}, i} d_{y, t, i} \text { hours }_{t} \quad \forall y, t, r_{1}, i \\
& \sum_{i=1}^{I} \text { init }_{r_{1}, i}+\sum_{u=1}^{y} \sum_{i=1}^{I}\left(s_{u, r_{1}, i}+\text { fnew }_{u, r_{1}, i}-\text { fretire }_{u, r_{1}, i}\right) \geq \text { peak }_{y, r_{1}} m_{y, r_{1}} \quad \forall y, r_{1} \\
& \sum_{t=1}^{T} \sum_{n=1}^{N} x_{y, t, r_{1}, n} \geq \operatorname{TMIN}_{y, r_{1}} \sum_{t=1}^{T} \sum_{i=1}^{I} x_{y, t, r_{1}, i} \quad \forall y, r_{1} \\
& \sum_{t=1}^{T} x_{y, t, r_{1}, n} \geq \operatorname{MIN}_{y, r_{1}, n} \sum_{t=1}^{T} \sum_{i=1}^{I} x_{y, t, r_{1}, i} \quad \forall y, r_{1}, n \\
& \sum_{t=1}^{T} \sum_{i=1}^{I} x_{y, t, r_{1}, i} E M_{e, i} \leq R L E M_{e, y, r_{1}} \quad \forall e, y, r_{1} \\
& s_{y, r_{1}, i} \leq C L_{y, r_{1}, i} \quad \forall y, r_{1}, i \\
& f_{y, t, r_{1}, r_{2}} \leq T L_{y, r_{1}, r_{2}} \text { hours } \quad \forall y, t, r_{1}, r_{2} \\
& x_{y, t, r_{1}, i} \geq 0, s_{y, r_{1}, i} \geq 0, f_{y, t, r_{1}, r_{2}} \geq 0 \quad \forall y, t, r_{1}, r_{2}, i
\end{aligned}
$$

The objective function (1) is to minimize the net present value of total costs over the planning time horizon. Equations (2) state that energy supplies should meet demand. Constraints (3) are capacity constraints, so that generation should not exceed the total capacity. Constraints (4) are reserve margin requirements, and constraints (5) and (6) represent RPS limits. Constraints (7) limit the generation emissions of $\mathrm{SO}_{2}, \mathrm{NO}_{\mathrm{x}}$, and $\mathrm{CO}_{2}$, while constraints (8) and (9) represent the construction and transmission capacity respectively, and (10) are nonnegativity constraints. 
Estimation of model parameters and coefficients originate from multiple sources such as EIPC (Figure 1, Tables 1-4), National Renewable Energy Laboratory (NREL) (Table 4), U.S. Environmental Protection Agency (EPA) (Table 4), U.S. Energy Information Administration (EIA) (Table 4). Some of the most important assumptions are shown in Figure 1, and Tables 1-4. Abbreviations of different generation technologies are given in Table 3 and the abbreviations are used throughout the remainder of the paper.

\subsection{Climate variables}

Three major climate variables relevant to power systems are selected and modeled in this research. In the Northeast U.S. region, temperature and precipitation are projected to increase with seasonal variation. The frequency and intensity of extreme events are also likely to increase. In general, increasing temperature, decreasing precipitation and increasing extreme events will reduce the capacity of the electric power generation system, as summarized in Table 5. We refer to a wide range of literature to identify how the climate change will affect different sectors of the power system and then predict the quantifiable impacts. They are important inputs to relate the scenario variables to the GEP model parameters. Previous research has presented the quantifiable impacts from climate variables on the GEP parameters in Tables 6-8 [4].

The projections of temperature, precipitation, extreme events and their impacts on the electric power generation system are briefly discussed with appropriate assumptions for those without specific literature references. We assume that the relationships between climate variables and GEP parameters are linear as an approximation based on past research studies reviewed by U.S. Department of Energy [3] which have made similar linear conclusions for individual variables. Uncertainty assumptions and expert projections are also subjected to spatial and temporal conditions. For example, there are many studies forecasting the electricity demand for California, but fewer for the Northeast U.S. area. For the extreme events, very few climate models have high confidence of future predictions. Thus, consistency of data and projections from various sources are not considered in this study given the scarcity of literature and 
published data. However, every parameter and coefficient value was selected based on a published source or data, or a reasonable assumption.

\subsection{Climate scenarios}

Five discrete scenarios are defined to approximate future climate conditions. Each climate scenario has three major climate variables: temperature, precipitation and extreme events, as shown in Table 9. The scenarios are mapped to six sets of uncertain GEP parameters that are influenced by climate change: demand, peak demand, capacity factor, transmission capacity, reserve margin and outage rate as described previously. Based on the existing published results $[3,5,6,7,8,9,10,45,46,47]$, we assume that temperature increases equally in different seasons, i.e., the literature shows little seasonal variation. Annual and summer precipitation is defined separately because summer precipitation is largely distinguished from annual precipitation. For extreme events, only the frequency of extreme events is included in the scenarios, since intensity and duration are difficult to model and project. It is noted that Scenario 1 is the extreme case, Scenario 5 is the base case, whereas Scenarios 2 and 3 are extracted from median expert projections of higher (A2) and lower (B1) emissions scenarios $[3,5,6,7,8,9,13$, $15,46,47]$.

The selection of five discrete scenarios involved a tradeoff between precision and available data. While the use of more scenarios could provide greater precision and more detail, it would also require more assumptions and estimates about future conditions which are inherently uncertain. A single scenario could be selected to provide an average consensus of available climate change projections. However, this could ignore the uncertainties and risks associated with climate change, and an important focus of this research is to specifically consider risk-aversion given those uncertainties. Based on all available data and projections, it was decided that five scenarios could represent the uncertainty and range of outcomes, while still being based on projections or justifiable extrapolations.

Scenarios 1-4 are distinguished based on the extent of climate change, whereas most of 
the non-climate-related GEP parameters are not changed. The six sets of climate-related uncertain GEP parameters are affected, which are summarized in Table 10. By comparing with the parameters in base case Scenario 5, Table 10 provides the additional yearly growth rate due to climate change.

Before the uncertainty of climate change is taken in to consideration, the preliminary deterministic GEP model is solved (using GAMS/CPLEX) under each scenario, as if it was known that each scenario is going to occur with certainty. We can then identify the deterministic optimal expansion plan and the climate change effect under each scenario. For example, the additional expansion costs under other scenarios are compared to Scenario 5 in Table 11, which summarizes the potential climate change effects.

\section{Extended Climate Change Model}

Stochastic optimization is widely and successfully used for decision making with parameter uncertainty. In this research, the uncertainty of climate change is characterized by the defined discrete climate scenarios. The model assumes that one of the climate scenarios will ultimately occur, and the set of uncertain parameters associated with each scenario could be observed in the future. The specific scenario that will occur is unknown at the time of the decision, and therefore, a compromise decision is made in advance. The objective of this problem is to select a solution that should be effective for any realization of the uncertainty in the given set of scenarios, e.g., five scenarios in this paper. The selected solution represents a compromise intended to neither spend too much for reliability considerations, nor pay too much penalty once one scenario occurs later. The traditional method to solve stochastic optimization is to minimize expected total cost, which is a risk-neutral approach and it is the first model presented in this paper. In some cases, a poor decision could lead to huge losses if a particular unlikely scenario does actually occur. In order to avoid undesirable outcomes of a poor decision, another method is to minimize the maximum regret. This is a risk-averse approach and it is the second model proposed. 
It is noted that certain constraints in the preliminary deterministic GEP model may be violated as we introduce uncertain parameters. Therefore new decision variables have been included: unmet demand and reserve margin requirements, and the amount of unavailable generation and transmission. The amount of unavailable generation and transmission is then translated as a part of the final unmet demands, hence only two types of penalty costs are considered in this study to avoid double counting, namely costs for unmet demand and costs for unmet reserve margin requirements.

In this paper, Model 1 is expected total cost minimization and Model 2 is maximum regret minimization. They have nearly the same sets of constraints but different objective functions. In both models, global constraints are used for all scenarios by incorporating penalty costs for each scenario. Scenario-based stochastic optimization is effective and practical because once probabilities are assigned to the discrete scenarios, the stochastic model can be transformed into an equivalent linear optimization model and solutions can be efficiently determined. Both models are transformed into equivalent linear programming models, intended to select a good compromise solution from risk-neutral and risk-averse perspectives, respectively.

\subsection{Expected total cost minimization model}

The objective function of the expected total cost minimization model (Equation 11) is to minimize the expected total present value of all costs including the penalty costs. The total costs include four parts: investment costs of the new construction, electricity generation costs, operation and maintenance costs, and penalty costs. The first three parts that represent the total expansion costs of the compromise optimal solution are the same as the preliminary model. The fourth part is the expected total penalty costs. 


$$
\begin{aligned}
\text { min Expected COST } & =\sum_{y=1}^{Y}\left(( 1 + r ) ^ { - y + 1 } \left(\sum_{t=1}^{T} \sum_{r_{1}=1}^{R} \sum_{i=1}^{I} x_{y, t, r_{1}, i} c_{y, i}+\sum_{r_{1}=1}^{R} \sum_{i=1}^{I} s_{y, r_{1}, i} a_{y, i}\right.\right. \\
& +\sum_{r_{1}=1}^{R} \sum_{i=1}^{I}\left(\sum_{u=1}^{y}\left(s_{u, r_{1}, i}+\text { fnew }_{u, r_{1}, i}\right)\right) h_{y, i}+\sum_{r_{1}=1}^{R} \sum_{i=1}^{I}\left(\text { init }_{r_{1}, i}-\sum_{u=1}^{y} \text { fretir }_{u, r_{1}, i}\right) g_{y, i} \\
& \left.\left.+\sum_{j=1}^{J} p_{j}\left(\sum_{t=1}^{T} \sum_{r_{1}=1}^{R} U D_{y, t, r_{1}, j} V D_{y}+\sum_{r_{1}=1}^{R} U R_{y, r_{1}, j} V R_{y}\right)\right)\right)
\end{aligned}
$$

\subsection{Maximum regret minimization model}

Regret is the difference between the net present value for any scenario based on a compromise solution and the corresponding net present value that would have been realized if decisions were made with advance knowledge that a particular scenario was to occur. Realization of any individual scenario leads to a different regret value, and we are most interested in the maximum regret among the different scenarios. Here we present another optimization model: a minmax problem, which finds the maximum regret over all scenarios and minimizes it (Equation 12). In this case, no probabilistic assumption is needed. From the perspective of regret, the maximum regret case does not necessarily imply the most extreme scenario. The regret is largely dependent on the compromise decision made considering the uncertainty. For example, if the optimal solution for the most extreme scenario is the same or very close to the compromise solution, then there would be very little or no regret if the extreme scenario happens, but potentially large regret for other scenarios because there could be overcapacity.

In our study, regret of one particular scenario is interpreted as the difference between the optimal cost, previously determined assuming that each scenario was known to occur, and the realized cost associated with the compromise solution made under uncertainty. If one particular scenario is certain to happen, the preliminary deterministic GEP model can be solved to obtain the optimal solution under that scenario. However, at the time a decision has to be made, uncertainty is inherent in the realization of any climate scenario. After the compromise solution is determined initially, the model assumes that one of the future scenarios will actually occur 
(but it is unknown which one), and the penalty costs can be observed. If we compare the realized cost and deterministic optimal cost, the regret can be computed as the difference.

$$
\begin{aligned}
\min \max _{j} \text { REG RET }=\sum_{y=1}^{Y}\left(( 1 + r ) ^ { - y + 1 } \left(\sum_{t=1}^{T} \sum_{r_{1}=1}^{R} \sum_{i=1}^{I} x_{y, t, r_{1}, i} c_{y, i}+\sum_{r_{1}=1}^{R} \sum_{i=1}^{I} s_{y, r_{1}, i} a_{y, i}\right.\right. \\
+\sum_{r_{1}=1}^{R} \sum_{i=1}^{I}\left(\sum_{u=1}^{y}\left(s_{u, r_{1}, i}+\text { fnew }_{u, r_{1}, i}\right)\right) h_{y, i}+\sum_{r_{1}=1}^{R} \sum_{i=1}^{I}\left(\text { init }_{r_{1}, i}-\sum_{u=1}^{y} \text { fretire }_{u, r_{1}, i}\right) g_{y, i} \\
\left.\left.+\sum_{t=1}^{T} \sum_{r_{1}=1}^{R} U D_{y, t, r_{1}, j} V D_{y}+\sum_{r_{1}=1}^{R} U R_{y, r_{1}, j} V R_{y}\right)\right)- \text { Optimal }_{j}
\end{aligned}
$$

A linear programming reformulation is performed to achieve linearity. The original minmax problem has been transformed to a minimization problem by introducing a new decision variable Maxregret and adding a group of constraints (14) corresponding to the $J$ scenarios. Other constraints remain the same. The objective function and new constraints are as follows.

$$
\text { min Maxregret }
$$

s.t.

$$
\begin{aligned}
& \sum_{y=1}^{Y}\left(( 1 + r ) ^ { - y + 1 } \left(\sum_{t=1}^{T} \sum_{r_{1}=1}^{R} \sum_{i=1}^{I} x_{y, t, r_{1}, i} c_{y, i}+\sum_{r_{1}=1}^{R} \sum_{i=1}^{I} s_{y, r_{1}, i} a_{y, i}\right.\right. \\
& +\sum_{r_{1}=1}^{R} \sum_{i=1}^{I}\left(\sum_{u=1}^{y}\left(s_{u, r_{1}, i}+\text { fnew }_{u, r_{1}, i}\right)\right) h_{y, i}+\sum_{r_{1}=1}^{R} \sum_{i=1}^{I}\left(\text { init }_{r_{1}, i}-\sum_{u=1}^{y} \text { fretire }_{u, r_{1}, i}\right) g_{y, i} \\
& \left.\left.+\sum_{t=1}^{T} \sum_{r_{1}=1}^{R} U D_{y, t, r_{1}, j} V D_{y}+\sum_{r_{1}=1}^{R} U R_{y, r_{1}, j} V R_{y}\right)\right)- \text { Optimal }_{j} \leq \text { Maxregret } \forall j
\end{aligned}
$$

\subsection{Constraints}

The two optimization models share most of the constraints (15-23). The only difference is (14) after the reformulation described in the previous section. Compared to the preliminary deterministic model, minmax regret models have more decision variables and parameters associated with each scenario. Constraints (15-17) and (22) differ from (2-4) and (9) due to the uncertainty of scenarios. These constraints are as follows. 


$$
\begin{aligned}
& \sum_{i=1}^{I}\left(x_{y, t, r_{1}, i}-U G_{y, t, r_{1}, i, j}\right)-\sum_{r_{2}=1}^{R}\left(f_{y, t, r_{1}, r_{2}}-U T_{y, t, r_{1}, r_{2}, j}\right) \\
& +\sum_{r_{2}=1}^{R}\left(f_{y, t, r_{2}, r_{1}}-U T_{y, t, r_{2}, r_{1}, j}\right)+U D_{y, t, r_{1}, j}=\varphi_{y, t, r_{1}, j} \quad \forall y, t, r_{1}, j \\
& x_{y, t, r_{1}, i} \leq\left(\text { init }_{r_{1}, i}+\sum_{u=1}^{y}\left(s_{u, r_{1}, i}+\text { fnew }_{u, r_{1}, i}-\text { fretire }_{u, r_{1}, i}\right)\right) c f_{y, t, r_{1}, i, j} d_{y, t, i, j} \text { hours }_{t} \\
& +U G_{y, t, r_{1}, i, j} \quad \forall y, t, r_{1}, i, j \\
& \sum_{i=1}^{I} \text { init }_{r_{1}, i}+\sum_{u=1}^{y} \sum_{i=1}^{I}\left(s_{u, r_{1}, i}+\text { fnew }_{u, r_{1}, i}-\text { fretire }_{u, r_{1}, i}\right)+U R_{y, r_{1}, j} \geq \text { peak }_{y, r_{1}, j} m_{y, r_{1}, j} \quad \forall y, r_{1}, j \\
& \sum_{t=1}^{T} \sum_{n=1}^{N} x_{y, t, r_{1}, n} \geq \operatorname{TMIN}_{y, r_{1}} \sum_{t=1}^{T} \sum_{i=1}^{I} x_{y, t, r_{1}, i} \quad \forall y, r_{1} \\
& \sum_{t=1}^{T} x_{y, t, r_{1}, n} \geq M I N_{y, r_{1}, n} \sum_{t=1}^{T} \sum_{i=1}^{I} x_{y, t, r_{1}, i} \quad \forall y, r_{1}, n \\
& \sum_{t=1}^{T} \sum_{i=1}^{I} x_{y, t, r_{1}, i} E M_{e, i} \leq R L E M_{e, y, r_{1}} \quad \forall e, y, r_{1} \\
& s_{y, r_{1}, i} \leq C L_{y, r_{1}, i} \quad \forall y, r_{1}, i \\
& f_{y, t, r_{1}, r_{2}} \leq T L_{y, r_{1}, r_{2}, j} \text { hours } s_{t}+U T_{y, t, r_{1}, r_{2}, j} \quad \forall y, t, r_{1}, r_{2}, j \\
& x_{y, t, r_{1}, i} \geq 0, s_{y, r_{1}, i} \geq 0, f_{y, t, r_{1}, r_{2}} \geq 0, U D_{y, t, r_{1}, j} \geq 0 \\
& U G_{y, t, r_{1}, i, j} \geq 0, U R_{y, r_{1}, j} \geq 0, U T_{y, t, r_{1}, r_{2}, j} \geq 0, \quad \forall y, t, r_{1}, r_{2}, i, j
\end{aligned}
$$

Compared to (2), equations (15) allow unmet demands if the generation and the transmission electricity amount associated with the compromise solution cannot meet the demands in some scenarios. Constraints (16) are capacity constraints, which allow unavailable capacity if generation exceed the total capacity in some scenarios. Constraints (17) are reserve margin requirement constraints that allow unmet capacity. Constraints (18-21) remain the same as (5-8). Constraints (22) represent transmission capacity limits that allow unavailable transmission in some scenarios, while (23) are nonnegative constraints.

\section{Numerical Examples}

To demonstrate and evaluate the models and optimization, numerical examples are tested and compared in this section. While most of the assumptions are consistent with the preliminary model, some additional assumptions were required to solve the test problems. The cost of unmet 
demand is normally called Value of Lost Load (VoLL), typically with a range of $\$ 1,000$ 20,000/MWh [48]. Here we assume the unmet demand cost to be $\$ 2,000 / \mathrm{MWh}$ (in 2010 dollars) with a growth rate of $2 \%$ as a reasonable value, while the cost of unmet reserve margin requirements is assumed to be 1.5 times the investment cost of a combustion turbine. The combustion turbine has the lowest investment cost, and to meet the reliability requirements, it is desirable to invest in the most economic technology. Scenarios 1 through 5 have probabilities of $0.1,0.3,0.3,0.2,0.1$. We assume that Scenario 1 is the extreme case with 0.1 probability, and Scenario 5 is also less probable as climate change is occurring. Scenarios 2 and 3 originate from the projections of experts, and they are assigned larger probabilities. The assumed probabilities are reasonable values, but only used for demonstration purposes. GAMS/CPLEX is used to solve the optimization models.

Solutions from both models represent a compromise between the extreme scenario and the other four scenarios in terms of investments, generation and total expansion costs. Compromise solutions tend to reserve more capacity in NU and WT_on3 (see Table 3) in case of extreme weather. It is also interesting to compare the results of these two optimization models. From the perspective of penalty costs, the expected total cost minimization model provides a more satisfactory solution as shown by the blue bar in Figure 2, especially since their expansion total costs are quite close. The expected total cost minimization model only has penalty costs applied in Scenarios 1 and 5, while the other model has more penalty costs in nearly every scenario.

On the other hand, the maximum regret minimization model (red bar) does provide a solution with least maximum regret around 29.7 billion in 2010 dollars, but it is not a significant improvement compared to the highest regret of 31.7 billion in 2010 dollars shown by the blue bar. Therefore, it has higher regret on average. Meanwhile, the maximum regret minimization model provides an equal regret under each scenario, which means that there will be a certain regret for any realized scenario. This indeed diminishes the uncertainty or variance; however, 
policy makers may not favor it as the average penalty cost and regret are both higher.

For our regret model, all scenarios have the same regret in the optimal solution. This is not an uncommon result in models to minimize the maximum regret. During the optimization process for a particular solution (not the optimal), variable values are changed or revised to decrease the highest regret, which causes a corresponding increase in regret for some other scenario until they are equal. Then other variables are changed to simultaneously minimize both of the highest regrets causing an increase in a third and/or fourth scenario, and so on. The optimization often continues until they are all equal, and any and all changes after that will cause the regret to increase for at least one scenario, i.e., the maximum increases.

A sensitivity analysis is conducted to investigate the extent to which the results can be generalized. We examine the probability and unit penalty cost sensitivities on a simple basis to compare the two models. The sensitivity analysis design is listed in Table 12, in which we label every combination of conditions as A through F. The models are then re-solved for each combination A through F.

Under a low unit penalty cost assumption, B has a much lower expansion cost (Table 13) as it is assumed that the extreme scenario is very unlikely to occur. Therefore, solution B is an optimistic decision. However, once Scenario 1 occurs as shown in Figure 3, there are extreme penalty and regret associated with Scenario 1. Another important conclusion that can be observed in Figure 3 is that, although solution B has a very large penalty and regret in Scenario 1, for Scenarios 2-5 solution B provides seemingly negative regrets. From a mathematical perspective, it is impossible to cost less than the optimal solution for each scenario. However, the reason for this apparently contradictory result is that the initial deterministic model does not allow any unmet demand, unavailable capacity or unmet reserve margin requirements, while the new model allows that with the limitation that penalty costs should be included. Consequently, compromise solution B chooses to pay a penalty instead of investment or generation, and the corresponding costs are lower even with the penalty. 
The unit penalty costs are then increased and the same models are solved again. The results show that probabilities are not significantly affecting the compromise solutions (Figure 4, Table 13). D and $\mathrm{E}$ have almost the same results in expansion, penalty costs and regrets. Both $\mathrm{D}$ and $\mathrm{E}$ lead to large regrets when the extreme scenario occurs. Solution $\mathrm{F}$ is much better in this case, as it only spends 4 billion 2010 dollars more but yields much lower regrets in return, except that it has penalties for Scenarios 2-5. Compromise solutions D and E only have penalties in Scenario 1, but have regrets in all scenarios.

We may infer from the previous results that the expected total cost minimization model is desired under a low unit penalty cost case. On the contrary, the maximum regret minimization model performs better under a high unit penalty cost case. These implications cannot necessarily be generalized because there are many different types of problems and associated issues.

\section{Conclusions and Discussion}

In this research, a detailed study of electric power generation expansion planning considering uncertainty of climate change has been conducted. Climate change has been a serious global concern as it has long-term effects on human systems. While it is gaining notable research interest in recent years, most studies concerned with the electric power system ignore the impact of climate change and its importance, or only conduct simple statistical modeling based on historical demand data. The uncertainties of climate change not only influence the demand for electricity, but also supply, reliability and some related factors, which requires systematic stochastic modeling and efficient solution methods.

The GEP models in this paper are representative of a vertical integrated electricity market which is less applicable currently, at least in the USA. However, from the perspective of policy makers, the models and results provide informative references and quantitative benchmarks, and allow for a study of the policy implications for power system planning and uncertainty modeling. Particularly as EPA announced the CPP in August 2015, the proposed models provide a valuable tool for regional planning authorities regarding power system 
reliability and risk management in response to climate change.

We present two optimization formulations: expected total cost minimization and maximum regret minimization models. Five climate scenarios have been defined based on the quantifiable relationships between climate variables and GEP parameters extracted from the projections of experts. Both models provide good compromise solutions with different performances under different configurations of GEP parameters.

The models presented in this paper reflect the best available information and do address climate change in both the models and the resulting solutions. However, the research is limited by the complexity of the GEP problems and preciseness of climate projections. The results provide a reference for power system modeling under uncertainty and risk management.

\section{Acknowledgements}

This research was supported from a National Science Foundation (NSF) Grant under Award Number: OCE 1049088.

\section{References}

[1] H. Tekiner, D. W. Coit and F. A. Felder, "Multi-period multi-objective electricity generation expansion planning problem with Monte-Carlo simulation," Electric Power Systems Research, vol. 80, no. 12, pp. 1394-1405, 2010.

[2] S. Parkpoom, G. P. Harrison and J. W. Bialek, "Climate and weather uncertainty in the electricity industry," International Energy Journal, vol. 6, no. 1, pp. 4:56-64, 2005.

[3] DOE, U.S. Energy Sector Vulnerabilities to Climate Change and Extreme Weather, Washington, DC: U.S. Department of Energy, Office of Policy and International Affairs, 2013.

[4] S. Li, D. W. Coit, F. A. Felder and S. Selcuklu, "Electric Power Generation Expansion Planning: Robust Optimization Considering Climate Change," in Proceedings of the 2014 Industrial and Systems Engineering Research Conference, Montreal, Canada, 2014.

[5] USGCRP, Global Climate Change Impacts in the United States, T. R. Karl, J. M. Melillo and T. C. Peterson, (eds.), Cambridge, UK: Cambridge University Press, 2009.

[6] IPCC, N. Nakićenović, Special report on emissions scenarios, Cambridge: Cambridge University Press, 2000.

[7] IPCC, Managing the risks of extreme events and disasters to advance climate change adaptation, $\mathrm{C}$. B. Field, V. Barros, T. F. Stocker and Q. Dahe, (eds.), Cambridge: Cambridge University Press, 2012.

[8] NOAA, Regional Climate Trends and Scenarios for the U.S. National Climate Assessment, Part 9. Climate of the Contiguous United States, Washington, DC: U.S. Department of Commerce, National Oceanic and Atmospheric Administration, 2013.

[9] NOAA, Regional Climate Trends and Scenarios for the U.S. National Climate Assessment, Part 1. Climate of the Northeast U.S., Washington, DC: U.S. Department of Commerce, National Oceanic and Atmospheric Administration, 2013.

[10] NCADAC, Federal advisory committee draft climate assessment, Washington, DC: National Climate Assessment Development Advisory Committee, 2013.

[11] S. N. Chandramowli and F. A. Felder, "Impact of climate change on electricity systems and markets 
- A review of models and forecasts," Sustainable Energy Technologies and Assessments, vol. 5, pp. 62-74, 2014.

[12] K. Pilli-Sihvola, P. AAtola, M. Ollikainen and H. Tuomenvirta, "Climate change and electricity consumption - witnessing increasing or decreasing use and costs?" Energy Policy, vol. 38, no.5, pp. 2409-2419, 2010.

[13] G. Franco and A. Sanstad, Climate change and electricity demand in California. Sacramento, CA: California Energy Commission, 2006.

[14] T. Ahmed, K. M. Muttaqi and A. P. Agalgaonkar, "Climate change impacts on electricity demand in the State of New South Wales, Australia," Applied Energy, vol. 98, pp. 376-383, 2012.

[15] NWCOUNCIL, Sixth Northwest Conservation and Electric Power Plan, Portland, Oregon: Northwest Power and Conservation Council, 2010.

[16] CCSP, Effects of climate change on energy production and use in the United States, A report by the U.S. Climate Change Science Program and the subcommittee on Global Change Research, T. J. Wilbanks, V. Bhatt, D. E. Bilello, S. R. Bull, J. Ekmann, W. C. Horak, Y. J. Huang, M. D. Levine, M. J. Sale, D. K. Schmalzer and M. J. Scott, (eds.), Washington, DC: U.S. Department of Energy, Office of Biological \& Environmental Research, 2007.

[17] F. Urban and T. Mitchell, "Climate change, disasters and electricity generation," IDS, 2011.

[18] J. A. Bloom, "Long-range generation planning using decomposition and probabilistic simulation," IEEE Transactions on Power Apparatus and Systems, vol. PAS-101, no. 4, pp. 797-802, 1982.

[19] J. A. Bloom, "Solving an electricity generating capacity expansion planning problem by generalized Benders' decomposition," Operations Research, vol. 31, no. 1, pp. 84-100, 1983.

[20] J. Sirikum, A. Techanitisawad and V. Kachitvichyanukul, "A new efficient GA-Benders' decomposition method: for power generation expansion planning with emission controls," IEEE Transactions on Power Systems, vol. 22, no. 3, pp. 1092-1100, 2007.

[21] A. G. Kagiannas, D. Th. Askounis and J. Psarras, "Power generation planning: a survey from monopoly to competition," Electrical Power and Energy System, vol. 26, no. 6, pp. 413-421, 2004.

[22] A. S. Chuang, F. Wu and P. Varaiya, "A game-theoretic model for generation expansion planning: problem formulation and numerical comparisons," IEEE Transactions on Power Systems, vol. 16, no. 4, pp. 885-891, 2001.

[23] S. Kannan, S. M. R. Slochanal and N. P. Padhy, "Application and comparison of metaheuristic techniques to generation expansion planning problem”, IEEE Transactions on Power Systems, vol. 20, no. 1 , pp. 466-475, 2005.

[24] S. Kannan, S. M. R. Slochanal, P. Subbaraj and N. P. Padhy, "Application of particle swarm optimization technique and its variants to generation expansion planning problem," Electric Power Systems Research, vol. 70, no. 3, pp. 203-210, 2004.

[25] Y. Fukuyama and H. D. Chiang, "A parallel genetic algorithm for generation expansion planning," IEEE Transactions on Power Systems, vol. 11, no. 2, pp. 955-961, 1996.

[26] Y. M. Park, J. R. Won, J. B. Park and D. G. Kim, "Generation expansion planning based on an advanced evolutionary programming," IEEE Transactions on Power Systems, vol. 14, no. 1, pp. 299-305, 1999.

[27] J. B. Park, Y. M. Park, J. R. Won and K. Y. Lee, "An improved genetic algorithm for generation expansion planning," IEEE Transactions on Power Systems, vol. 15, no. 3, pp. 916-922, 2000.

[28] B. F. Hobbs, "Optimization methods for electric utility resource planning," European Journal of Operational Research, vol. 83, no. 1, pp. 1-20, 1995.

[29] J. Aghaei, M. A. Akbari, A. Roosta and A. Baharvandi, "Multiobjective generation expansion planning considering power system adequacy," Electric Power Systems Research, vol. 102, pp. 819, 2013.

[30] G. A. Bakirtzis, P. N. Biskas and V. Chatziathanasiou, "Generation Expansion Planning by MILP considering mid-term scheduling decisions," Electric Power Systems Research, vol. 86, pp. 98-112, 2012.

[31] E. G. Cazalet, "Decomposition of complex decision problems with applications to electrical power 
system planning," Ph.D. dissertation, Engineering-Economic Systems Department, Stanford University, Stanford, CA, 1970.

[32] A. B. Borison, P. A. Morris and S. S. Oren, "A state-of-the world decomposition approach to dynamics and uncertainty in electric utility generation expansion planning," Operations Research, vol. 32, no. 5, pp. 1052-1068, 1984.

[33] B. G. Gorenstin, N. M. Campodonico, J. P. Costa and M. V. F. Pereira, "Power system expansion planning under uncertainty," IEEE Transactions on Power Systems, vol. 8, no. 1, pp. 129-136, 1993.

[34] S. A. Malcolm and S. A. Zenios, "Robust optimization for power systems capacity expansion under uncertainty," The Journal of the Operational Research Society, vol. 45, no. 9, pp. 1040-1049, 1994.

[35] W. Buehring, C. Huber and J. Marques de Souza, Expansion planning for electrical generating systems: a guidebook (Technical Reports Series no. 241), Vienna: International Atomic Energy Agency, 1984.

[36] B. Mo, J. Hegge and I. Wangensteen, "Stochastic generation expansion planning by means of stochastic dynamic programming," IEEE Transactions on Power Systems, vol. 6, no. 2, pp. 662668, 1991.

[37] C. T. Su, G. R. Lii and J. J. Chen, "Long-term generation expansion planning employing dynamic programming and fuzzy techniques," Industrial Technology 2000. Proceedings of IEEE International Conference on, vol. 2, pp. 644-649, 2000.

[38] S. Rebennack, "Generation expansion planning under uncertainty with emissions quotas," Electric Power Systems Research, vol. 114, pp. 78-85, 2014.

[39] A. J. C. Pereira and J. T. Saraiva, "A long term generation expansion planning model using system dynamics - Case study using data from the Portuguese/Spanish generation system," Electric Power Systems Research, vol. 97, pp. 41-50, 2013.

[40] S. Ahmed, A. J. King and G. Parija, "A multi-stage stochastic integer programming approach for capacity expansion under uncertainty," Journal of Global Optimization, vol. 26, no. 1, pp. 3-24, 2003.

[41] H. Aissi, C. Bazgan and D. Vanderpooten, "Approximation of min-max and min-max regret versions of some combinatorial optimization problems," European Journal of Operational Research, vol. 179, no. 2, pp. 281-290, 2007.

[42] I. Averbakh, "Minmax regret solutions for minimax optimization problems with uncertainty," Operations Research Letters, vol. 27, no. 2, pp. 57-65, 2000.

[43] P. Bean and D. Hoppock, Least-risk planning for electric utilities, Beaufort, NC: Nicholas Institute for Environmental Policy Solutions, 2013.

[44] R. Jiang, J. Wang, M. Zhang and Y. Guan, "Two-Stage Minimax Regret Robust Unit Commitment," IEEE Transactions on Power Systems, vol. 28, no. 3, pp. 2271-2282, 2013.

[45] F. Urban and T. Mitchell, "Climate change, disasters and electricity generation," IDS, 2011.

[46] D. Cayan, A. L. Luers, M. Hanemann, G. Franco and B. Croes, Scenarios of climate change in California: an overview, Sacramento, CA: California Energy Commission, 2006.

[47] M. T. H. van Vliet, J. R. Yearsley, F. Ludwig, S. Vögele, D. P. Lettenmaier and P. Kabat, "Vulnerability of US and European electricity supply to climate change," Nature Climate Change, vol. 2, no. 9, pp. 676-681, 2012.

[48] M. J. Sullivan, M. Mercurio and J. Schellenberg, Estimated value of service reliability for electric utility customers in the United States, Berkeley, CA: Energy Analysis Department, Environmental Energy Technologies Division, Ernest Orlando Lawrence Berkeley National Laboratory, 2009. 


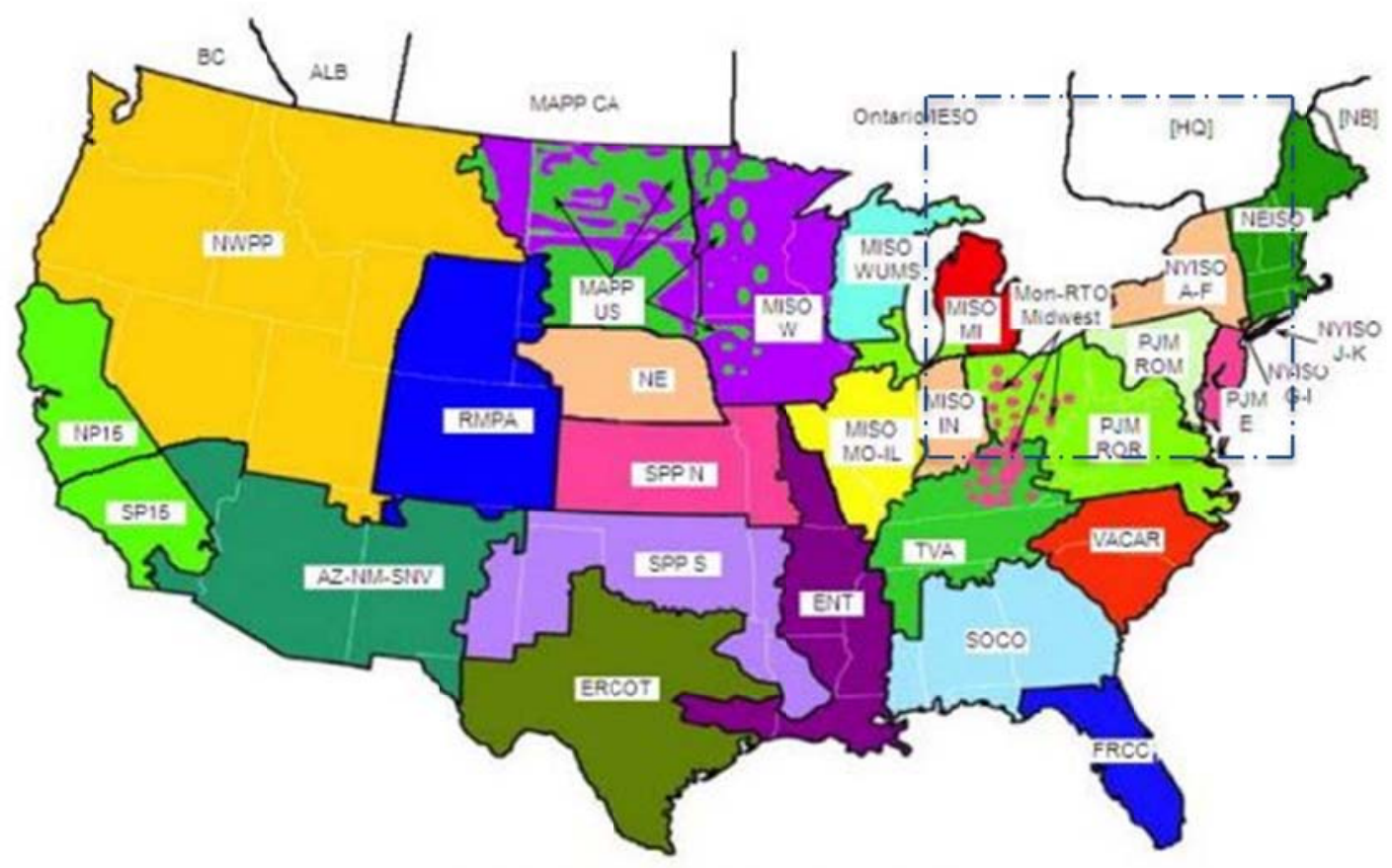

Figure 1. Map of considered areas in the model

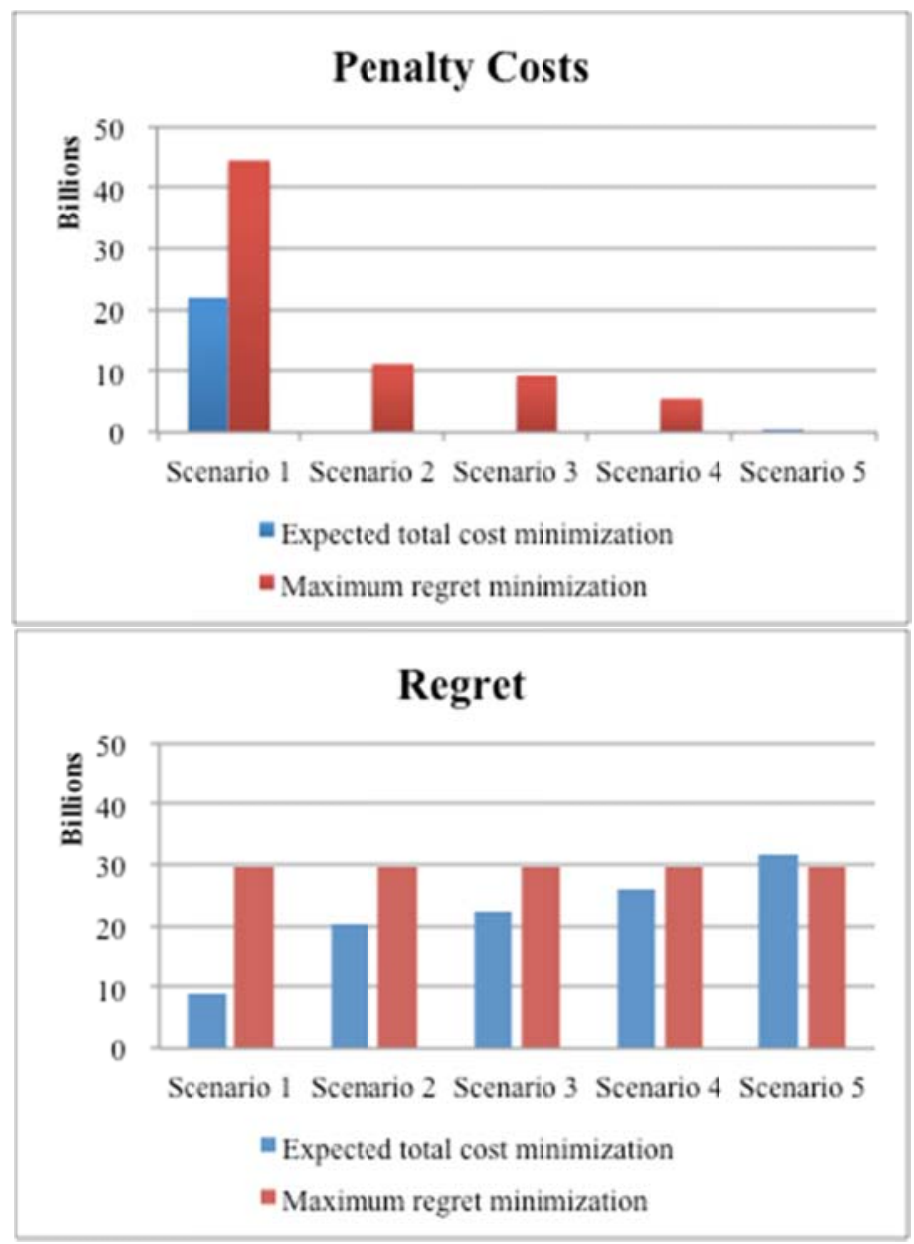

Figure 2. Penalty and regret comparison (Billion 2010\$) 


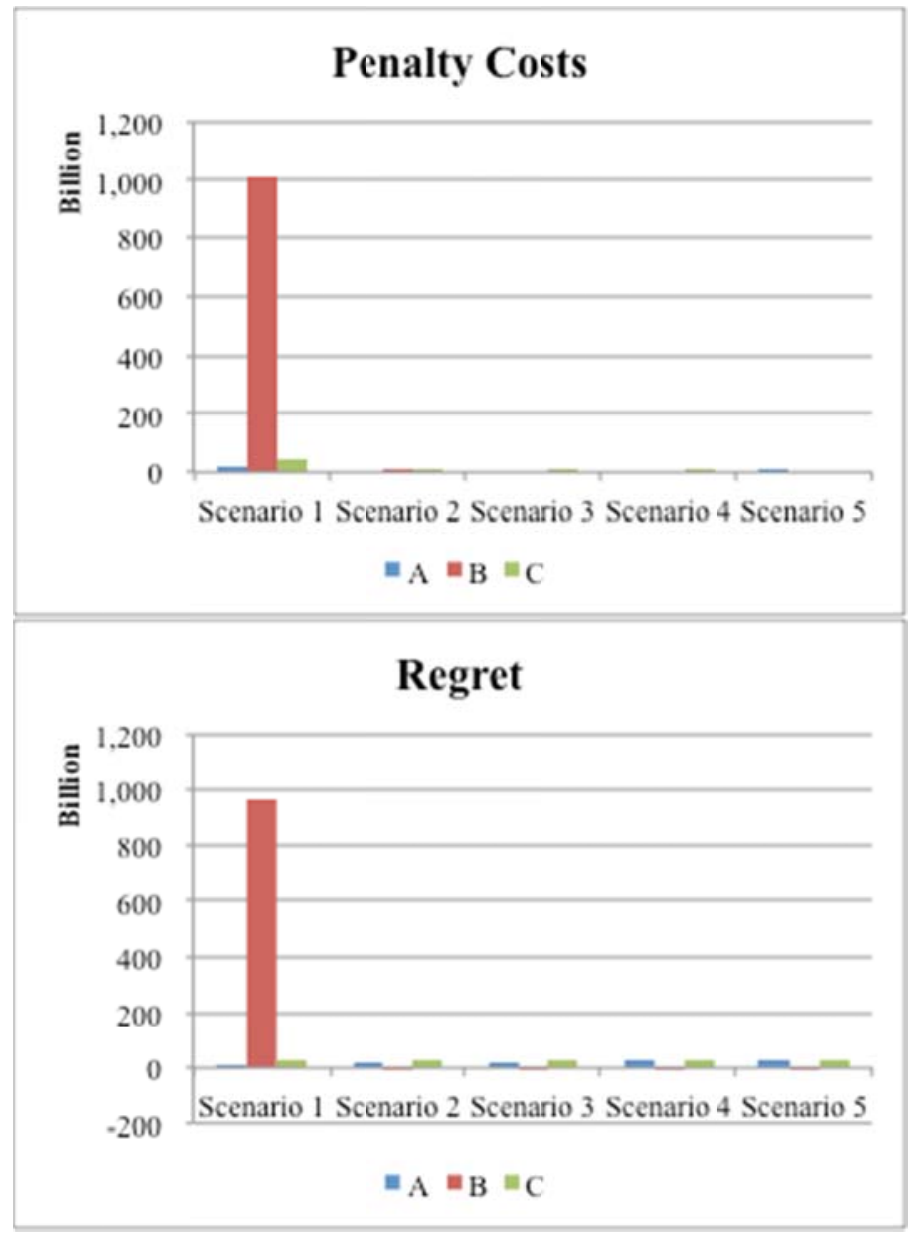

Figure 3. Penalty/regret under low unit penalty cost for A, B \& C 2010-2040 (Billion 2010\$) 


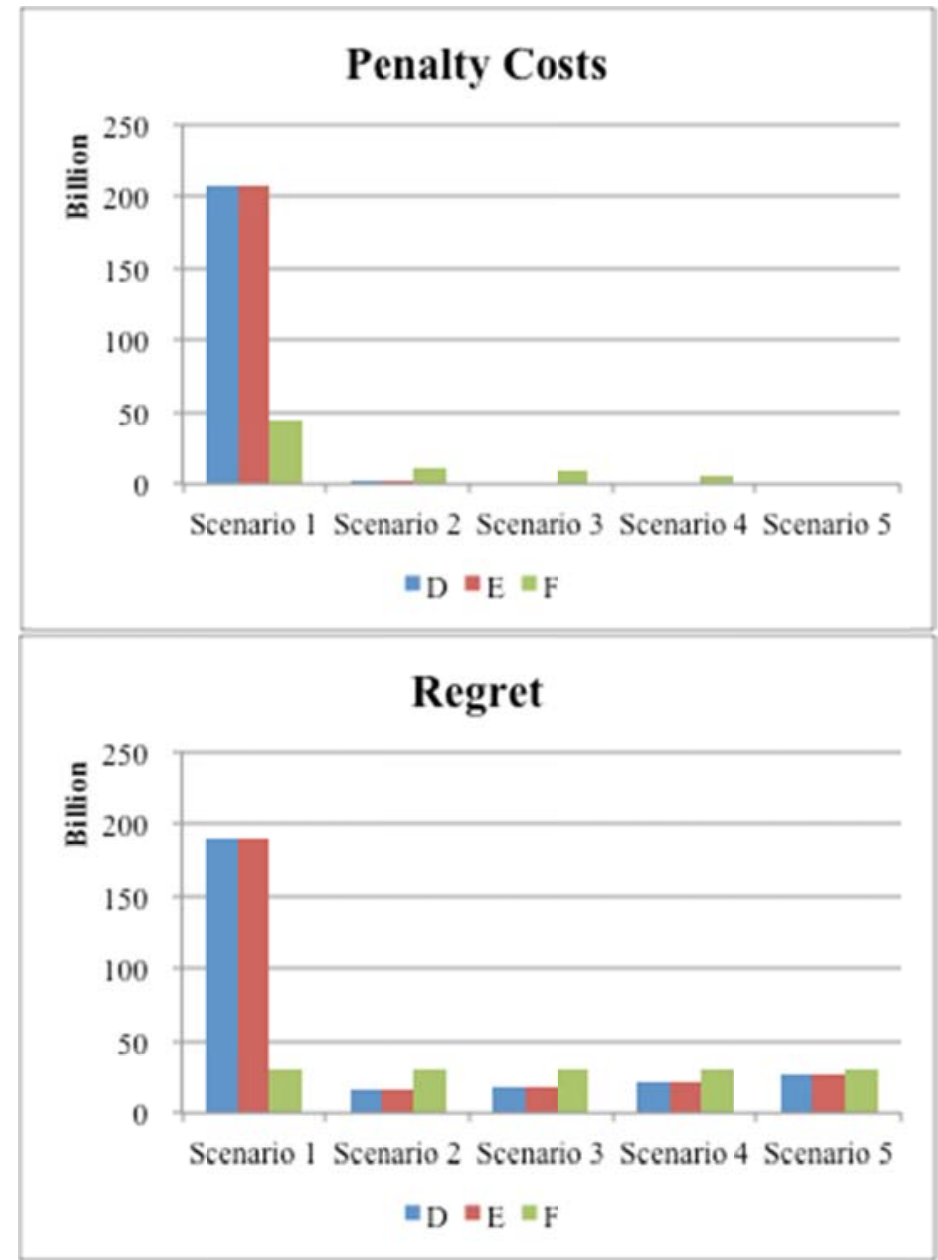

Figure 4. Penalty/regret under high unit penalty cost for D, E \& F 2010-2040 (Billion 2010\$)

Table 1. Electricity demands and peak demands in 2010 (GWh)

\begin{tabular}{cccccccc}
\hline & NEISO & NYISO_A-F & NYISO_G-I & NYISO_J-K & PJM_E & PJM_ROM & PJM_ROR \\
\hline Summer-peak & 30,115 & 14,710 & 5,048 & 19,759 & 38,078 & 35,124 & 124,635 \\
Summer-offpeak & 23,953 & 12,918 & 4,001 & 15,185 & 29,507 & 28,614 & 102,943 \\
Shoulder-peak & 20,773 & 10,908 & 3,266 & 12,162 & 23,305 & 23,731 & 84,720 \\
Shoulder-offpeak & 18,014 & 9,985 & 2,858 & 10,495 & 20,819 & 21,511 & 78,294 \\
Winter-peak & 16,628 & 8,687 & 2,601 & 9,229 & 18,642 & 19,527 & 68,549 \\
Winter-offpeak & 14,608 & 8,021 & 2,329 & 8,196 & 16,948 & 17,856 & 63,614 \\
\hline Peak (MW) & 26,043 & 11,455 & 4,356 & 17,030 & 32,910 & 27,332 & 99,146 \\
\hline
\end{tabular}

Table 2. Electricity load growth rate

\begin{tabular}{|c|c|c|c|c|c|c|c|}
\hline & NEISO & NYISO_A-F & NYISO_G-I & NYISO_J-K & PJM_E & PJM_ROM & PJM_ROR \\
\hline \multicolumn{8}{|c|}{ Annual load growth } \\
\hline $2010-2020$ & $0.23 \%$ & $0.2 \%$ & $0.14 \%$ & $0.39 \%$ & $-0.98 \%$ & $0.86 \%$ & $0.4 \%$ \\
\hline 2021-2040 & $0 \%$ & $0.51 \%$ & $0.85 \%$ & $0.88 \%$ & $0.67 \%$ & $0.67 \%$ & $0.61 \%$ \\
\hline \multicolumn{8}{|c|}{ Peak load growth } \\
\hline 2010-2020 & $0.49 \%$ & $0.1 \%$ & $-0.09 \%$ & $0.1 \%$ & $-0.92 \%$ & $0.71 \%$ & $0.42 \%$ \\
\hline 2021-2040 & $0.12 \%$ & $0.51 \%$ & $0.85 \%$ & $0.88 \%$ & $0.67 \%$ & $0.67 \%$ & $0.61 \%$ \\
\hline
\end{tabular}


Table 3. Abbreviations of generation technologies

\begin{tabular}{|c|c|c|}
\hline & Generation Type & Description \\
\hline \multirow{13}{*}{ Existing } & $\mathrm{CC}$ & Combined Cycle - Natural Gas \\
\hline & Coal & Steam Turbine - Coal \\
\hline & $\mathrm{CT}$ & Combustion Turbine - Natural Gas or Oil \\
\hline & GEO (Renewable) & Geothermal \\
\hline & HY (Renewable) & Hydro - Conventional \\
\hline & LFG (Renewable) & Landfill Gas \\
\hline & $\mathrm{NU}$ & Nuclear \\
\hline & PS (Renewable) & Hydro - Pumped Storage \\
\hline & PV (Renewable) & Solar - Photovoltaic \\
\hline & ST (Renewable) & Solar - Solar Thermal/Solar Power \\
\hline & STOG & Steam Turbine - Oil/Gas \\
\hline & STWD & Steam Turbine - Wood \\
\hline & WT (Renewable) & Wind Turbine onshore \\
\hline \multirow{7}{*}{ New } & WT_on3 (Renewable) & Wind Turbine (onshore class 3 wind) \\
\hline & WT_on4 (Renewable) & Wind Turbine (onshore class 4+ wind) \\
\hline & WT_off (Renewable) & Wind Turbine offshore \\
\hline & IGCC & Integrated Gasification Combined Cycle \\
\hline & IGCC_seq & IGCC with carbon capture/sequestration \\
\hline & $\mathrm{AC}$ & Advanced or Pulverized Coal \\
\hline & Biomass (Renewable) & Biomass \\
\hline
\end{tabular}

Note: WT on3 and WT on4 are both onshore wind turbine technologies but have different target wind resources. Depending on the wind power, wind can be divided into different classes, and we consider class 3 and class $4+$ wind. They are only distinguished for new generation units.

Table 4. Characteristics of all generation technologies

\begin{tabular}{|c|c|c|c|c|c|c|c|c|}
\hline \multirow{2}{*}{ Type } & \multirow{2}{*}{$\begin{array}{c}\text { Forced } \\
\text { outage rate }\end{array}$} & \multirow{2}{*}{$\begin{array}{c}\text { Inv. cost } \\
(2010 \$ / \mathrm{kW})\end{array}$} & \multicolumn{2}{|c|}{ Fixed OM $(2010 \$ / \mathrm{kW})$} & \multirow{2}{*}{$\begin{array}{c}\text { Var. cost } \\
(2010 \$ / \mathrm{MWh})\end{array}$} & $\mathrm{SO}_{2}$ & \multirow{2}{*}{\multicolumn{2}{|c|}{$\begin{array}{l}\mathrm{NO}_{\mathrm{X}} \mathrm{CO}_{2} \\
(\mathrm{lbs} / \mathrm{MWh})\end{array}$}} \\
\hline & & & Existing & New & & & & \\
\hline $\mathrm{CC}$ & $6.1 \%$ & 1,035 & 29.68 & 14.39 & 47.45 & 0.1 & 1.7 & 1,135 \\
\hline Coal & $6.5 \%$ & - & 48.22 & - & 28.63 & 13 & 6 & 2,249 \\
\hline CT & $9 \%$ & 711 & - & 6.7 & 78.43 & 0.66 & 2.9 & 1,565 \\
\hline GEO & $13 \%$ & 4,163 & 89.76 & 84.27 & 0 & 0 & 0 & 0 \\
\hline $\mathrm{HY}$ & $4.9 \%$ & - & 14.24 & - & 0 & 0 & 0 & 0 \\
\hline LFG & $5 \%$ & 2,525 & 120.65 & 120.33 & 0 & 0.8 & 5.4 & 2,988 \\
\hline NU & $3.2 \%$ & 5,615 & 112.77 & 88.75 & 12.06 & 0 & 0 & 0 \\
\hline PS & $4 \%$ & - & 23.74 & - & 5.98 & 0 & 0 & 0 \\
\hline PV & $60 \%$ & 4,777 & 14.66 & 16.7 & 0 & 0 & 0 & 0 \\
\hline $\mathrm{ST}$ & $1 \%$ & 4,714 & 60.32 & 64 & 0 & 0 & 0 & 0 \\
\hline STOG & $6.7 \%$ & - & 37.15 & - & 58.82 & 3 & 2.4 & 1,325 \\
\hline STWD & $10 \%$ & - & 32.05 & - & 78.43 & 3 & 4 & 1562 \\
\hline WT & $0 \%$ & - & 34.22 & 28.07 & 0 & 0 & 0 & 0 \\
\hline WT_on3 & $0 \%$ & 2,460 & 34.22 & 28.07 & 0 & 0 & 0 & 0 \\
\hline WT_on4 & $0 \%$ & 2,460 & 34.22 & 28.07 & 0 & 0 & 0 & 0 \\
\hline WT_off & $0 \%$ & 5,997 & - & 53.33 & 0 & 0 & 0 & 0 \\
\hline $\mathrm{IG} \overline{\mathrm{C}} \mathrm{C}$ & $8 \%$ & 3,262 & - & 48.9 & 44.12 & 0.13 & 0.4 & 1,540 \\
\hline IGCC_seq & $8 \%$ & 5,389 & - & 69.3 & 53.04 & 0.13 & 0.4 & 154 \\
\hline $\mathrm{A} \overline{\mathrm{C}}$ & $6 \%$ & 2,885 & - & 29.67 & 30.1 & 0.13 & 1.6 & 1,540 \\
\hline Biomass & $7.5 \%$ & 3,901 & - & 100.5 & 41.47 & 28.6 & 11 & 0 \\
\hline
\end{tabular}

Note: Forced outage rate is the estimated average probability that a generation unit is unavailable under a normal weather assumption (i.e. base case Scenario 5). Investment costs are not listed for some technologies where investments are prohibited. 
Table 5. Relationship between climate change projects and implications for GEP parameters

\begin{tabular}{|c|c|c|c|}
\hline Climate change trend & Impact & GEP parameters & Implication \\
\hline \multirow{5}{*}{ Increasing temperature } & \multirow{2}{*}{$\begin{array}{l}\text { Electricity } \\
\text { generation }\end{array}$} & $\begin{array}{l}\text { Thermal power generation capacity } \\
\text { factors }\end{array}$ & Reducing thermal efficiencies \\
\hline & & Solar photovoltaic capacity factor & $\begin{array}{l}\text { Reducing efficiency of the } \\
\text { semiconducting material }\end{array}$ \\
\hline & Power grid & Transmission loss & $\begin{array}{c}\text { Decreasing transmission } \\
\text { capacity }\end{array}$ \\
\hline & \multirow{2}{*}{$\begin{array}{l}\text { Electricity } \\
\text { demand }\end{array}$} & Demand & $\begin{array}{l}\text { Lower heating demand, higher } \\
\text { cooling demand }\end{array}$ \\
\hline & & Peak demand & Higher peak demand \\
\hline \multirow{2}{*}{$\begin{array}{l}\text { Decreasing } \\
\text { precipitation }\end{array}$} & $\begin{array}{l}\text { Electricity } \\
\text { generation }\end{array}$ & $\begin{array}{l}\text { Thermal power generation capacity } \\
\text { factors }\end{array}$ & $\begin{array}{l}\text { Decreasing cooling water for } \\
\text { thermal generation }\end{array}$ \\
\hline & Hydropower & Hydropower capacity factor & Decreasing streamflow \\
\hline \multirow{4}{*}{$\begin{array}{l}\text { Increasing frequency of } \\
\text { extreme events (storm, } \\
\text { flooding, heat wave, } \\
\text { wildfire) }\end{array}$} & $\begin{array}{l}\text { Electricity } \\
\text { generation }\end{array}$ & Outage rate & $\begin{array}{l}\text { More storms and flooding and } \\
\text { potential wear }\end{array}$ \\
\hline & Power grid & Transmission loss & Storms/wildfire damage \\
\hline & Electricity & Reserve margin & Reliability requirement \\
\hline & demand & Peak demand & Extreme heat wave \\
\hline
\end{tabular}

Table 6. Magnitude of impact from temperature on GEP parameters [4]

\begin{tabular}{|c|c|c|}
\hline & GEP Parameters & Impact \\
\hline \multirow{11}{*}{ Temperature $\left(+1^{\circ} \mathrm{C}\right)$} & \multirow{6}{*}{ Capacity factor } & Coal, STOG, STWD, AC (-0.1\%) \\
\hline & & CT $(-0.65 \%)$ \\
\hline & & CC, IGCC, IGCC seq $(-0.4 \%)$ \\
\hline & & GEO, LFG, Biomass (-0.1\%) \\
\hline & & PV, ST $(-0.65 \%)$ \\
\hline & & NU $(-0.5 \%)$ \\
\hline & Transmission capacity & $(-1.5 \%)$ \\
\hline & Annual demand & $(+2.2 \%)$ \\
\hline & Summer demand & $(+2.7 \%)$ \\
\hline & Winter demand & $(-2.3 \%)$ \\
\hline & Peak demand & $(+2.9 \%)$ \\
\hline
\end{tabular}

Table 7. Magnitude of impact from precipitation on GEP parameters [4]

\begin{tabular}{lll}
\hline & GEP Parameters & Impact \\
\hline & & Coal, CT, STOG, STWD, AC (-2.5\%) \\
\cline { 2 - 2 } Precipitation (-1\%) & Capacity factor & NU, ST, GEO, LFG, Biomass (-3\%) \\
\cline { 2 - 2 } & & HY (-6\%) \\
\hline
\end{tabular}

Table 8. Magnitude of impact from extreme events frequency on GEP parameters [4]

\begin{tabular}{lll}
\hline & GEP Parameters & Impact \\
\hline \multirow{3}{*}{ Frequency $(+100 \%)$} & Outage rate & Maintenance time $(+20 \%)$ \\
\cline { 2 - 3 } & Transmission capacity & $(-3 \%)$ \\
\cline { 2 - 3 } & Reserve margin & $(+10 \%)$ \\
\cline { 2 - 3 } & Peak demand & $(+5 \%)$ \\
\hline
\end{tabular}

Table 9. Climate scenarios summary by 2035, with respect to 1971-2000 [4]

\begin{tabular}{c|c|cc|c}
\hline Scenario & Temperature & \multicolumn{2}{|c|}{ Precipitation } & Extreme events \\
\hline & Annual & Annual & Summer & Frequency \\
$\mathbf{1}$ & $+4.4^{\circ} \mathrm{C}$ & $+12 \%$ & $-4 \%$ & $+300 \%$ \\
$\mathbf{2}$ & $+1.7^{\circ} \mathrm{C}$ & $+4 \%$ & $+1 \%$ & $+75 \%$ \\
$\mathbf{3}$ & $+1.5^{\circ} \mathrm{C}$ & $+3 \%$ & $+2 \%$ & $+50 \%$ \\
$\mathbf{4}$ & $+1.0^{\circ} \mathrm{C}$ & $+2 \%$ & $+0 \%$ & $+10 \%$ \\
$\mathbf{5}$ & As present & As present & As present & As present \\
\hline
\end{tabular}


Table 10. Additional yearly growth rates due to climate change, with respect to Scenario 5

\begin{tabular}{|c|c|c|c|c|c|}
\hline & Scenario & 1 & 2 & 3 & 4 \\
\hline \multirow{3}{*}{ Additional demand growth } & Summer & $+0.24 \%$ & $+0.092 \%$ & $+0.081 \%$ & $+0.054 \%$ \\
\hline & Shoulder (spring/fall) & $+0.19 \%$ & $+0.075 \%$ & $+0.066 \%$ & $+0.044 \%$ \\
\hline & Winter & $-0.2 \%$ & $-0.078 \%$ & $-0.069 \%$ & $-0.046 \%$ \\
\hline Additional peak demand growth & & $+0.56 \%$ & $+0.175 \%$ & $+0.137 \%$ & $+0.068 \%$ \\
\hline $\begin{array}{l}\text { Additional reserve margin } \\
\text { requirement }\end{array}$ & & $+0.6 \%$ & $+0.15 \%$ & $+0.1 \%$ & $+0.02 \%$ \\
\hline Additional maintenance time & & $+1.2 \%$ & $+0.3 \%$ & $+0.2 \%$ & $+0.04 \%$ \\
\hline Additional transmission loss & & $+0.31 \%$ & $+0.096 \%$ & $+0.075 \%$ & $+0.036 \%$ \\
\hline \multirow{8}{*}{$\begin{array}{l}\text { Additional summer capacity } \\
\text { factor decrease }\end{array}$} & Coal, STOG, STWD, AC & $-0.209 \%$ & - & - & - \\
\hline & CT & $-0.257 \%$ & - & - & - \\
\hline & CC, IGCC, IGCC seq & $-0.099 \%$ & - & - & - \\
\hline & GEO, LFG, Biomass & $-0.249 \%$ & - & - & - \\
\hline & $\mathrm{PV}$ & $-0.057 \%$ & - & - & - \\
\hline & $\mathrm{NU}$ & $-0.284 \%$ & - & - & - \\
\hline & ST & $-0.297 \%$ & - & - & - \\
\hline & $\mathrm{HY}$ & $-0.48 \%$ & - & - & - \\
\hline \multirow{7}{*}{$\begin{array}{c}\text { Additional shoulder (spring/fall) } \\
\text { and winter capacity factor } \\
\text { decrease }\end{array}$} & Coal, STOG, STWD, AC & $-0.009 \%$ & $-0.003 \%$ & $-0.003 \%$ & $-0.002 \%$ \\
\hline & $\mathrm{CT}$ & $-0.057 \%$ & $-0.022 \%$ & $-0.02 \%$ & $-0.013 \%$ \\
\hline & CC, IGCC, IGCC_seq & $-0.035 \%$ & $-0.014 \%$ & $-0.012 \%$ & $-0.008 \%$ \\
\hline & GEO, LFG, Biomass & $-0.009 \%$ & $-0.003 \%$ & $-0.003 \%$ & $-0.002 \%$ \\
\hline & $\mathrm{NU}$ & $-0.044 \%$ & $-0.017 \%$ & $-0.015 \%$ & $0.01 \%$ \\
\hline & $\mathrm{PV}$ & $-0.057 \%$ & $-0.022 \%$ & $-0.02 \%$ & $-0.013 \%$ \\
\hline & ST & $-0.057 \%$ & $-0.022 \%$ & $-0.02 \%$ & $-0.013 \%$ \\
\hline
\end{tabular}

Table 11. Total expansion cost in each scenario 2010-2040

\begin{tabular}{cccccc}
\hline & Scenario 1 & Scenario 2 & Scenario 3 & Scenario 4 & Scenario 5 \\
\hline Expansion cost (2010\$ Billion) & 968.06 & 934.85 & 932.97 & 929.18 & 923.61 \\
\hline Climate change cost (2010\$ Billion) & 44.45 & 11.24 & 9.36 & 5.57 & 0.00 \\
Climate change effect & $4.81 \%$ & $1.22 \%$ & $1.01 \%$ & $0.60 \%$ & $0.00 \%$ \\
\hline
\end{tabular}

Table 12. Sensitivity analysis design

\begin{tabular}{cccc}
\hline & \multicolumn{2}{c}{ Expected toal cost minimization } & Maximum regret minimization \\
\cline { 2 - 3 } & $\begin{array}{c}\text { More extreme } \\
\left(p_{1}=0.1\right)\end{array}$ & $\begin{array}{c}\text { Less extreme } \\
\left(p_{1}=0.02\right)\end{array}$ & $\mathrm{C}$ \\
\hline $\begin{array}{c}\text { Low unit penalty cost } \\
(2000 \$ \mathrm{MWh})\end{array}$ & $\mathrm{A}$ & $\mathrm{B}$ & $\mathrm{F}$ \\
$\begin{array}{c}\text { High unit penalty cost } \\
(5000 \$ \mathrm{MWh})\end{array}$ & $\mathrm{D}$ & $\mathrm{E}$ & $\mathrm{F}$ \\
\hline
\end{tabular}

Table 13. Expansion costs for A-F 2010-2040 (Billion 2010\$)

\begin{tabular}{cccc}
\hline & \multicolumn{2}{c}{ Expected toal cost minimization } & Maximum regret minimization \\
\cline { 2 - 3 } & $\begin{array}{c}\text { More extreme } \\
\left(p_{1}=0.1\right)\end{array}$ & $\begin{array}{c}\text { Less extreme } \\
\left(p_{1}=0.02\right)\end{array}$ & C (953.33) \\
\hline $\begin{array}{c}\text { Low unit penalty cost } \\
(2000 \$ \text { MWh })\end{array}$ & A (955.10) & B $(923.08)$ & F (954.32) \\
$\begin{array}{c}\text { High unit penalty cost } \\
(5000 \$ \text { MWh })\end{array}$ & D (950.01) & E (950.01) & \\
\hline
\end{tabular}

